\title{
Disease monitoring programs of rare genetic diseases: transparent data sharing between academic and commercial stakeholders
}

\author{
Hanns Lochmüller ${ }^{1,2,3^{*}}$ (D), Antonio Nino Ramirez ${ }^{4}$ and Emil Kakkis ${ }^{4}$
}

\begin{abstract}
It has recently been suggested that registries for rare neuromuscular diseases should be formed and governed exclusively by physicians and patients in an effort to limit conflicts of interest. Enacting such an approach would not only be challenging logistically and financially, but it would also exclude the involvement of sponsors, who are an integral component of drug development within the current compliance framework. Therefore, as an alternative to traditional registries, we propose the use of a better collaborative model for post-marketing follow-up that includes all stakeholders. We developed the concept of Disease Monitoring Programs (DMPs), which are designed to monitor disease manifestations over a 10-year period whether on a sponsored drug or not, and ensure consistent collection, ownership sharing and governance of data.
\end{abstract}

Keywords: Orphan drugs, Registry, Registries, Data sharing, Disease monitoring program, DMP, GNE myopathy, GNE myopathy disease monitoring program, GNEM-DMP

Hollak et al. have provided a provocative argument that registries for orphan drugs designed by pharmaceutical companies are tainted by conflicts of interest since they are conducted by the sponsors of a product [1]. This is not an entirely new concept, as some early examples related to lysosomal storage diseases may demonstrate, e.g., competing product-specific registries by different companies, poor data quality, insufficient recruitment, lack of transparency and lack of data sharing. We do appreciate and agree that the proprietary approach taken by many sponsors in conducting these registries does not advance the understanding and treatment of rare diseases as well as it should, and could be improved. The International Rare Disease Research Consortium (IRDiRC)

\footnotetext{
*Correspondence: hanns.lochmuller@gmail.com

${ }^{1}$ Children's Hospital of Eastern Ontario Research Institute, Ottawa, Canada Full list of author information is available at the end of the article
}

representing public and private research funders and patient organizations from around the world, provided guidance and best-practice examples to a more effective, transparent, and balanced approach, including governance, data sharing, and data linkage models $[2,3]$. We disagree with the authors' proposed solution of registries formed and governed exclusively by physicians and patients for several reasons. While Hollak et al. implied biased decisions and lack of data disclosure, the substitution of the academic world and patient groups to conduct such registries would not solve the problem and has rarely been successfully done in an effective and appropriately compliant manner, due not only to the millions of Euros required but also to the numerous diverse professionals required to conduct such studies that are rarely present in most academic institutions. The pharmaceutical industry sponsored registries are required to be designed and conducted by sponsors as an integral original author(s) and the source, provide a link to the Creative Commons licence, and indicate if changes were made. The images or other third party material in this article are included in the article's Creative Commons licence, unless indicated otherwise in a credit line to the material. If material is not included in the article's Creative Commons licence and your intended use is not permitted by statutory regulation or exceeds the permitted use, you will need to obtain permission directly from the copyright holder. To view a copy of this licence, visit http://creativecommons.org/licenses/by/4.0/. The Creative Commons Public Domain Dedication waiver (http://creativeco mmons.org/publicdomain/zero/1.0/) applies to the data made available in this article, unless otherwise stated in a credit line to the data. 
part of the whole drug development process within the legal regulatory and compliance framework exerted by US Food and Drug Administration, European Medicines Agency, and other regulators to ensure that the studies abide by the requirements that society imposes on drug developers to maintain a license to operate. To extract the pharmaceutical sponsors from registries for rare diseases would not solve the problem, nor would it end the need for the pharmaceutical sponsors to conduct the registries to meet their regulatory requirements. We would propose instead a more efficient and transparent collaboration between regulatory agencies, academia, industry, clinicians, and patient advocacy groups to optimize the long-term follow-up of disease manifestations and product outcomes.

We advocate for a new model of registries where collaboration exists in which the pharmaceutical sponsor partners with a major physician organization on the ownership and management of data and forms a steering committee of stakeholders to manage the evaluation and processing of data and requests for evaluation. We call these studies Disease Monitoring Programs (DMP) to distinguish them from traditional registries. The DMPs are intended to monitor disease manifestations over a 10 -year period in patients both on a sponsored drug, or on other treatment, or not treated at all, in a comprehensive GCP-monitored format where all measurements, tests, patient travel and physician effort is covered by the Sponsoring company, to assure the data are collected consistently as scheduled and not missing as happens in some academic programs. The GNE Myopathy Disease Monitoring Program (GNEMDMP) is an example of this DMP partnership between TREAT-NMD and Ultragenyx Pharmaceutical Inc. (USA), with shared ownership of data governed by a collaboration agreement $[4,5]$. The GNEM-DMP began before aceneuramic acid extended release was submitted for a marketing authorization and was used to collect natural history data across a number of countries but would also have potentially collected data for patients on a drug in the post-marketing setting. The use of the data in the GNEMDMP was governed by a team of researchers, physicians, and patient representatives from US, UK, Israel, and Japan who constitute the steering committee. The program aims to improve the medical knowledge of GNE myopathy and can be a model for future registries for rare diseases to gain knowledge on the natural history of the disease and the effect of all available treatments. In this specific program, the phase 3 study of the sponsored drug failed, and the dataset, conduct, and ownership of the DMP data was continued by TREAT-NMD with the data available to others as was agreed by the collaboration agreement. Any academic or industry researcher can request access to data, perform independent analysis, and publish findings free from influence of commercial sponsors once approved by the steering committee. We think this structured collaborative approach of a DMP can achieve a more productive and transparent outcome, taking the skills and contributions of each party to assure the greater interests of the patient community and society are met.

From our experience in rare and neuromuscular disease registries, successful public-private partnership models have been constructed in different ways. Ideally, these models should facilitate research at different stages of drug development and application, be flexible enough to adopt new research questions and new contributors, and have a long-term sustainability plan [6-8].

\section{Abbreviations \\ DMP: Disease monitoring program; GNEM-DMP: GNE myopathy disease moni- toring program; NMD: Neuromuscular disease.}

\section{Acknowledgements}

Ben Scott, PhD (Scott Medical Communications, LLC), provided editorial support funded by Ultragenyx Pharmaceutical Inc.

\section{Data sharing policy}

Not applicable.

\section{Authors' contributions}

All authors drafted the manuscript or substantially revised it and read and approved the final manuscript.

\section{Funding}

This work was funded by Ultragenyx Pharmaceutical Inc. HL receives support from the Canadian Institutes of Health Research (Foundation Grant FDN167281), the Canadian Institutes of Health Research and Muscular Dystrophy Canada (Network Catalyst Grant for NMD4C), the Canada Foundation for Innovation (CFI-JELF 38412), and the Canada Research Chairs program (Canada Research Chair in Neuromuscular Genomics and Health, 950-232279).

Availability of data and materials

Not applicable.

Ethics approval and consent to participate

Not applicable.

Consent for publication

Not applicable.

\section{Competing interests}

$\mathrm{HL}$-Consultancy and financial support for research projects and clinical trials from Amplo Biotechnology, AMO Pharma, Biogen, Desitin, Fulcrum Therapeutics, GW Pharma, Milo Biotechnology, Pfizer, PTC Therapeutics, Roche, Santhera, Sarepta, Satellos and Ultragenyx. Editor-in-chief for the Journal of Neuromuscular Disease (IOS Press). ANR and EK are employees of and shareholders in Ultragenyx Pharmaceutical Inc.

\section{Author details \\ ${ }^{1}$ Children's Hospital of Eastern Ontario Research Institute, Ottawa, Canada. ${ }^{2}$ Division of Neurology, Department of Medicine, The Ottawa Hospital, Ottawa, Canada. ${ }^{3}$ Brain and Mind Research Institute, University of Ottawa, Ottawa, Canada. ${ }^{4}$ Ultragenyx Pharmaceutical Inc., Novato, CA, USA.}

Received: 23 October 2020 Accepted: 6 January 2021

Published online: 20 March 2021 


\section{References}

1. Hollak CEM, Sirrs S, van den Berg S, van der Wel V, Langeveld M, Dekker $\mathrm{H}$, et al. Registries for orphan drugs: generating evidence or marketing tools? Orphanet J Rare Dis. 2020;15:235.

2. Lochmüller H, Le Cam Y, Jonker AH, Lau LP, Baynam G, Kaufmann P, et al. "IRDiRC Recognized Resources": a new mechanism to support scientists to conduct efficient, high-quality research for rare diseases. Eur J Hum Genet. 2017;25:162-5.

3. Lochmüller H, Torrent IFJ, Le Cam Y, Jonker AH, Lau LP, Baynam G, et al. The International Rare Diseases Research Consortium: policies and guidelines to maximize impact. Eur J Hum Genet. 2017:25:1293-302.

4. Pogoryelova O, Cammish P, Mansbach H, Argov Z, Nishino I, Skrinar A, et al. Phenotypic stratification and genotype-phenotype correlation in a heterogeneous, international cohort of GNE myopathy patients: First report from the GNE myopathy Disease Monitoring Program, registry portion. Neuromuscul Disord. 2018;28:158-68.

5. Lochmüller H,Behin A, Tournev I, Tarnopolsky M, Horváth R, Pogoryelova $O$ et al. Results from a 3-year non-interventional, observational disease monitoring program in adults with GNE myopathy. Submitted 2020 (under review).

6. Hodgkinson V, Lounsberry J, M'Dahoma S, Russell A, Benstead T, Brais B, et al. The Canadian Neuromuscular Disease Registry 2010-2019: a decade of facilitating clinical research through a nationwide, pan-neuromuscular disease registry. J Neuromuscul Dis. 2020;8:53-61.

7. Pechmann A, Konig K, Bernert G, Schachtrup K, Schara U, Schorling D, et al. SMArtCARE-a platform to collect real-life outcome data of patients with spinal muscular atrophy. Orphanet J Rare Dis. 2019;14:18.

8. Thompson R, Robertson A, Lochmuller H. Natural history, trial readiness and gene discovery: advances in patient registries for neuromuscular disease. Adv Exp Med Biol. 2017;1031:97-124.

\section{Publisher's Note}

Springer Nature remains neutral with regard to jurisdictional claims in published maps and institutional affiliations.
Ready to submit your research? Choose BMC and benefit from:

- fast, convenient online submission

- thorough peer review by experienced researchers in your field

- rapid publication on acceptance

- support for research data, including large and complex data types

- gold Open Access which fosters wider collaboration and increased citations

- maximum visibility for your research: over $100 \mathrm{M}$ website views per year

At BMC, research is always in progress.

Learn more biomedcentral.com/submissions 